\title{
sciforum
}

Conference Proceedings Paper

\section{The Mediterranean moisture supply in the genesis of climatological and extreme monthly continental precipitation}

\author{
Danica Ciric ${ }^{1, *}$, Raquel Nieto ${ }^{1, *}$, Lucia Losada ${ }^{1}$, Anita Drumond ${ }^{1}$, Luis Gimeno ${ }^{1}$ \\ Published: 06/11/2017 \\ Academic Editor: Ana María Durán-Quesada \\ 1 EPhysLab (Environmental Physics Laboratory), Facultade de Ciencias, Universidade de Vigo, \\ 32004 Ourense, Spain;lucialosadar@gmail.com (L.L.); anitadru@uvigo.es (A.D.); l.gimeno@uvigo.es (L.G.) \\ * Correspondence: cdanica@alumnos.uvigo.es (D.C.) ; rnieto@uvigo.es (R.N.); Tel.: +34-988-387-248
}

\begin{abstract}
The moisture transport from its sources to the continents is one of the most relevant topics in the hydrology, and its role in extremes events is crucial to understand several processes in the Earth, as intense precipitations and/or flooding. Using the global precipitation dataset from the Multi-Source Weighted-Ensemble Precipitation (MSWEP) from 1980 to 2015, a monthly precipitation climatology was done over the area of the Mediterranean Sea, checking grid by grid which year exhibits the maximum precipitation. As is well known, the Mediterranean Basin is a clear source of moisture for the surrounding areas. To link this source of moisture with the precipitation over it surroundings, in this work we have made use of the Lagrangian dispersion model FLEXPART to track, in its forward mode, those particles that monthly leave the Mediterranean Basin and we have calculated the loss of moisture $(\mathrm{E}-\mathrm{P}<0)$ modeled by FLEXPART over the continental region. The aim of this study is to calculate the monthly climatological percentage of the Mediterranean contribution grid by grid, and the changes of this contribution for extreme monthly precipitation, checking the importance of this sea source of moisture during the maxima peaks of precipitation. In general terms, the spatial pattern of the contribution of the Mediterranean source to the precipitation does not differ a lot between those years with higher precipitation and the climatology; however there any European regions where the Mediterranean is not an important source for climatological precipitation but it is a significant source for extreme precipitation years.
\end{abstract}

Keywords: extreme precipitation, Lagrangian approach, Mediterranean basin, moisture sinks.

\section{Introduction}

Moisture transport from the oceans to the continents, precipitation, and evaporation are important elements of the hydrological cycle [1]. Because of the huge importance of water resources on quality of human life, today exist a great interest among meteorologists and hydrologists in researching and understanding connection between evaporation and precipitation on the Earth [2].

The origin of the precipitation, which occurs in some area, may be explained through the presence of such (or more) of these factors: i) the moisture already exists in the atmosphere over the area, ii) the transport of moisture by winds from some region, or iii) the moisture recycling. When we look at a longer period, the contribution of the first source is very little, then we can say that the two major sources of moisture that are responsible for precipitation in a region are the advection and local evaporation [3]. 
The 1st International Electronic Conference on Hydrological Cycle (CHyCle-2017), 12-16 November 2017; Sciforum Electronic Conference Series, Vol. 1, 2017

Changes in global precipitation, and other categories of precipitation, will be one of the most significant factors to evaluate the global climate changes and their impacts. Currently, some findings say that high precipitation events have an increasing trend in intensity and/or frequency [4,5]. Extreme events (such as droughts, floods, landslides) and their changes in frequency and intensity, and changes in the water cycle lead to the some of the major economic losses and human fatalities in the Mediterranean area [6]. In concordance to that, the analysis of the extreme precipitation trends and changes of the moisture transport from the Mediterranean basin to different areas of the neighboring continents is relevant for the evaluation and prediction of high precipitation events.

The area of the Mediterranean basin can be determined by the countries surrounding the Mediterranean Sea, including the sea itself. The Mediterranean basin occupies 3,800 km east to west from the tip of Portugal to the shores of Lebanon, and 1,000 km north to south from Italy to Morocco and Libya, with an area of 2.5 million $\mathrm{km}^{2}$ and an average depth of $1,500 \mathrm{~m}$. The climate of Mediterranean varies by the geographic location and it is characterized by hot-dry summers and humid-cool winters. The mountainous terrain (highest pick in the Alps with a maximum high of $4,800 \mathrm{~m}$ ) around the Mediterranean basin (Figure 1) has a significant impact on the climate and meteorology in the region. Moreover, the complex land-sea distribution with many islands, peninsulas and inner seas around the basin [7], makes the region an interesting area in terms of meteorology due that they determine important consequences in the atmospheric circulation and they are the reason for many sub regional and mesoscale characteristics. The Mediterranean region is a very important area in many sectors and has a huge impact on human life, natural process and available water for different purposes [3], especially for the areas in Africa, Asia and Europe [8]. The knowledge of the Mediterranean hydrological cycle and its variability may have a positive effect on human quality and activity in the area of Mediterranean region and improve socioeconomic benefits to this area.

\section{Mediterranean Basin}
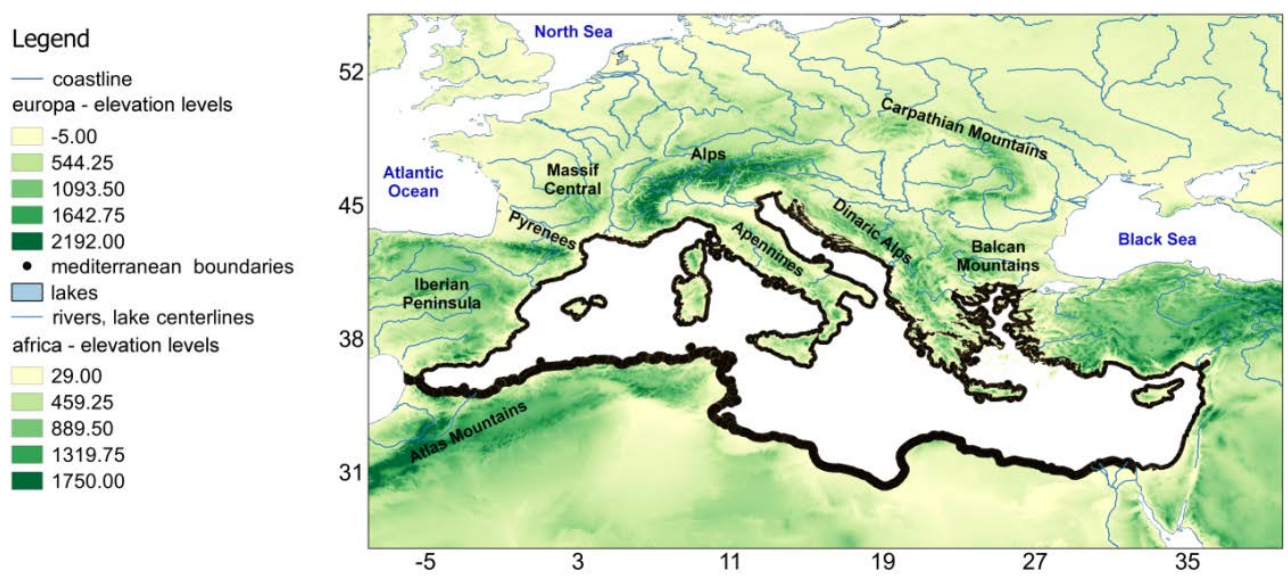

Figure 1. The black line contour indicates area of the Mediterranean Basin. Green colors represent elevation levels in meters (m). Data from the HydroSHEDS (Hydrological data and maps based on SHuttle Elevation Derivatives at multiple Scales) project (available online: https://hydrosheds.cr.usgs.gov).

Large-scale precipitation events in the western, central and eastern Mediterranean are related with local anomalies of high moisture over the Mediterranean Sea [9], and those are influenced by remote positive sources anomalies [10]. Many works pointed out the important role of remote sources for extreme precipitation events in the area of Mediterranean basin [10-13].

Heavy rainfalls over the Mediterranean basin are due by several factors as mesoscale convective systems, cyclones, upper synoptic-scale-level troughs, and large-scale circulation 
The 1st International Electronic Conference on Hydrological Cycle (CHyCle-2017), 12-16 November 2017; Sciforum Electronic Conference Series, Vol. 1, 2017

teleconnection patters [14-18]. At a local scale, the intensity of the precipitation depends on the temperature profile, the atmospheric moisture, and the convergence at lower levels; but it is the moisture content one of the essential components to generate intense precipitation, in combination with an intense convection [19].

In the Mediterranean region, around 90\% of heavy precipitation events are associated with cyclones [14]. During the period between September and May, which is characterized as well the most precipitative period during the year, the accumulated rainfall contributes more than $80 \%$ in the total annual precipitation [20, 21]. That is the case, for instance, for the Alpine region where during autumn and winter the Mediterranean Sea is one of the main precipitation sources for extreme precipitation [10]. In general, the higher frequency of extreme precipitations and their impacts are recorded in the north-western part of the basin [22].

Many studies were performed about trend in extreme precipitations. They have pointed out that extreme precipitation events in the Mediterranean region, their frequency, intensity and impact do not show a homogenous tendency on the entire area [22].

Alpert et al. [23] in their work have reported that significant increasing trends in torrential rainfall events are recorded in Spain $(>128 \mathrm{~mm}$ /day), heavy and torrential rainfall $(>64 \mathrm{~mm} /$ day) in Italian Peninsula, while for both regions is evidenced decreasing trends in light and moderated precipitation. Other findings which have studied climate extreme says that over the Italian Peninsula is evidenced positive trends in the number of days with precipitation amount more than $10 \mathrm{~mm}$, while negative trend is evidenced in the eastern part of the Mediterranean [24].

The Mediterranean Sea was identified as one of the main source of moisture for continental precipitation [1-3, 25-28].

In this study we have analyzed the percentage of the precipitation over the Mediterranean surrounding that is due by the moisture with a Mediterranean origin during near the last 40 decades (1980 to 2016) grid by grid with a resolution of 0.25 degrees in latitude and longitude, and we have computed the changes of this contribution for extreme monthly precipitation, in order to highlight the importance of this sea source of moisture during the maxima peaks of precipitation. Many works $[20,29-30]$ referred that for the Mediterranean region the most intense precipitations occur at the end of boreal summer, with the maximum values at the end of August, September or/and October. This is why this conference proceeding paper is focused on September, instead all the remaining month are computed.

To calculate the precipitation that comes from the Mediterranean Sea we used the Lagrangian FLEXPART V9.0 model developed by Stohl and James [31-32], and to compute the monthly precipitation the high resolution Multi-Source Weighted-Ensemble Precipitation (MSWEP) dataset was utilized. So, the main objectives of this work are: i) to quantify the contribution of the Mediterranean source of moisture to the precipitation over continental surrounding areas, and ii) to analyze the percentage of this source in the extreme precipitations grid by grid.

\section{Data and Method}

\subsection{MSWEP precipitation dataset}

In this work we used the monthly precipitation dataset Multi-Source Weighted-Ensemble Precipitation (MSWEP) [33-34] from January 1980 to December 2015, although only results for September were shown and described. MSWEP is a new precipitation dataset, which has been accessible since the beginning of 2017. The MSWP was developed to merge the highest quality of available precipitation data as a function of time scale and location. To determinate regions with the highest values of precipitation at monthly scale in a long time period, the resolution and precision of the database used is very important. The MSWEP database obtains precipitation information with the highest possible accuracy at global scale, which makes it unique in comparison with other databases. 
The 1st International Electronic Conference on Hydrological Cycle (CHyCle-2017), 12-16 November 2017; Sciforum Electronic Conference Series, Vol. 1, 2017

The MSWEP database is specially designed for hydrological modeling due its $0.25^{\circ} \times 0.25^{\circ}$ degree spatial resolution in latitude and longitude with a 3-hourly accumulated.

We have used MSWEP monthly precipitation dataset to compute the monthly climatological precipitation values over the Mediterranean region between 30W-65E and 5N-70N.Checking grid by grid for each individual month we made a ranking for the maximum precipitation. Taking into account only those 5 years with the most intense precipitation value for each grid point we have composed a climatology for this extreme years.

\subsection{Lagrangian moisture sinks for the Mediterranean Sea source}

The moisture sinks regions are computed using the Lagrangian FLEXPART V9.0 model [25-26] integrated with the ERA-Interim reanalysis data from the ECMWF(European Centre for Medium-Range Weather Forecast) [35]. The ERA-Interim dataset has $1^{\circ}$ spatial resolution on 60 vertical levels from 1000 to $0.1 \mathrm{hPa}$, available at each 6-hour time interval.

The method developed by Stohl and James [31-32] track the changes in specific humidity along the trajectories, which allow us the identification of moisture sources and sinks regions. The method is based in dividing the global atmosphere in approximately 2.0 million of particles (air masses) of constant mass $(\mathrm{m})$ which are moved along the trajectories using a three-dimensional wind field. The mean water vapour lifetime of the particles in the atmosphere were limited to 10 days and denote transport time of each particle along the trajectories [36]. The time changes in specific humidity (q) allow us to identify those particles that obtain moisture through evaporation (e) or lose moisture through precipitation ( $\mathrm{p})$. Changes in specific humidity may be given by equation:

$$
(\mathrm{e}-\mathrm{p}=\mathrm{m} \mathrm{dq} / \mathrm{dt})
$$

where $m$ represents the mass of the particle. By adding up (e-p) for all the particles which existing in the atmosphere over area of interest we can obtain instantaneous values of surface freshwater flux (E-P), where (E) denotes the rate of evaporation and (P) rate of precipitation per unit area.

In comparison to other similar approaches applied in moisture transport analysis (for example box models and isotopes) Gimeno et al. [37] pointed out that the Lagrangian approach is one of the most suitable tools to compute moisture source-sink relationships.

To identify the moisture sinks regions in Mediterranean area due to those moisture that comes from the Mediterranean Sea basin we conduct a forward in time experiment from January 1980 to December 2015. Using this mode to follow the particles from a specific area we can track the trajectories of the particles during 10 days with the aim of identifying those regions where the particles lost humidity (sinks regions, $\mathrm{E}-\mathrm{P}<0$ ) leaving a particular source. As for precipitation, only September results are shown.

\section{Results}

\subsection{Climatological and extreme MSWEP monthly precipitation}

To calculate the climatological value of monthly precipitation (Figure 2) we used the global precipitation database from MSWEP. The analysis covers the temporal period from 1980 to 2015 and in this work we put the focus on September, one of the months with the highest recorded precipitation in the Mediterranean region [21]. 


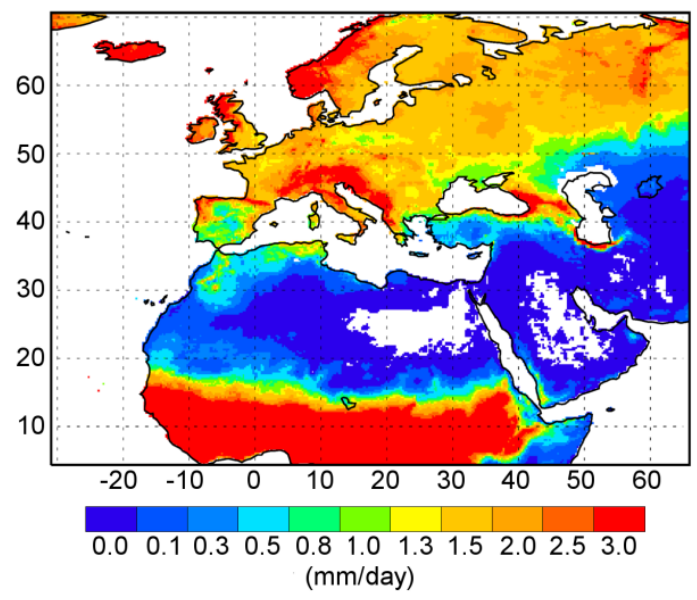

Figure 2. Monthly climatological value from MSWEP global precipitation database for September over the area of Mediterranean basin for 1980-2015.

Results show that the highest climatological values of precipitation (more than $2 \mathrm{~mm} /$ day) in September are recorded in Central Europe, Italian Peninsula, the Balkans, some parts of the Iberian Peninsula, Scandinavian Peninsula, the western part of Asia and Central Africa. Most of the precipitation over the Atlantic coast and northern Europe is typically due to fronts associated with midlatitude cyclones, and if they flow over the continent they can continue eastward up to Middle East [38]. The northern Mediterranean basin higher precipitations are due to convective events [10]. On the other hand, very low values of precipitation (lower than $0.3 \mathrm{~mm} /$ day) occur in the semi-arid and arid regions of Africa and Asia.

After the identification the climatological values, we have checked grid by grid the 5 years which exhibit the greatest values of precipitation. Mean values of these 5 years are shown in Figure 3.

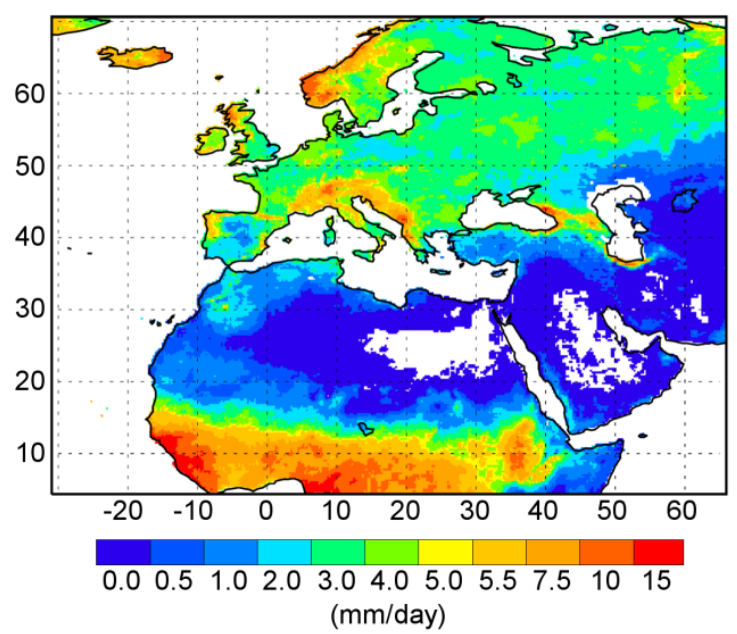

Figure 3. Mean precipitation for each grid point for the identified 5 years with the highest value of precipitation in September. Results are obtained from MSWEP precipitation dataset taking into account a 36 years temporal period (1980-2015).

This pattern exhibits a similar configuration as the climatological conditions (Figure 2). The highest values (more than $5.5 \mathrm{~mm} /$ day, orange colors) are observed around Italian Peninsula, Iberian Peninsula, Scandinavian Peninsula and in Central African region. For the East Europe and Western 
The 1st International Electronic Conference on Hydrological Cycle (CHyCle-2017), 12-16 November 2017; Sciforum Electronic Conference Series, Vol. 1, 2017

part of Asia the extreme precipitation values for the corresponding 5 years are in a range between 3 and $4 \mathrm{~mm}$ /day.

The ratio between them (MSWEP-Cli divided by MSWEP-extreme) are plotted in Figure 4. The ratio is higher in arid and semiarid regions of Northern Africa and Middle East where the MSWEP-Cli is very low, in these areas precipitation for extreme years can be even up to five times higher than the climatological values. Over Europe the ratio peaks in areas of the Iberian and Hellenic Peninsula with values of about 3. It is interesting the result showing that any of the lowest values of the ratio are reached on the Alpine regions where climatological precipitation in the highest.

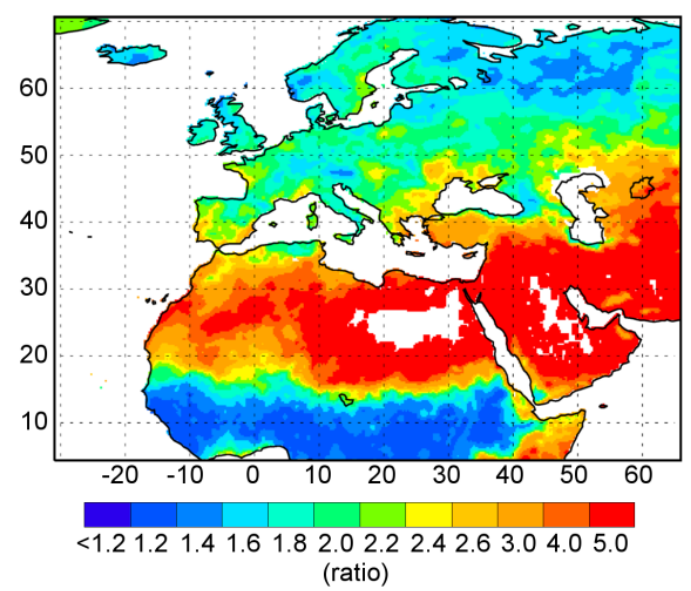

Figure 4. Ratio between mean values of detected 5 years for each grid point with the higher values of precipitation (MSWEP-extreme) and mean climatological values of precipitation (MSWEP-Cli) during September. White areas over continent indicate that MSWEP database does not show values.

\subsection{Climatological and extreme FLEXPART monthly precipitation with origin in the Meditterranean Sea}

To identify the major climatological monthly moisture sinks for the Mediterranean region, we tracked the air masses over the Mediterranean Sea forward in time for the period 1980-2015.Those areas where precipitation exceeds evaporation in the net moisture budget, $(\mathrm{E}-\mathrm{P})<0$, represent the moisture sinks regions. The climatological values of $(\mathrm{E}-\mathrm{P})<0$ integrated during the 10 days of the forward tracking for September (PFLEX) for the Mediterranean region are shown in Figure 5. These values are a good estimation to the precipitation generated by moisture coming from the Mediterranean Sea. The highest values are found in regions close to the Mediterranean (reddish colors, $>0.6 \mathrm{~mm} /$ day) over the north-western coast, Tunisian, Libyan, and Middle East coast. 


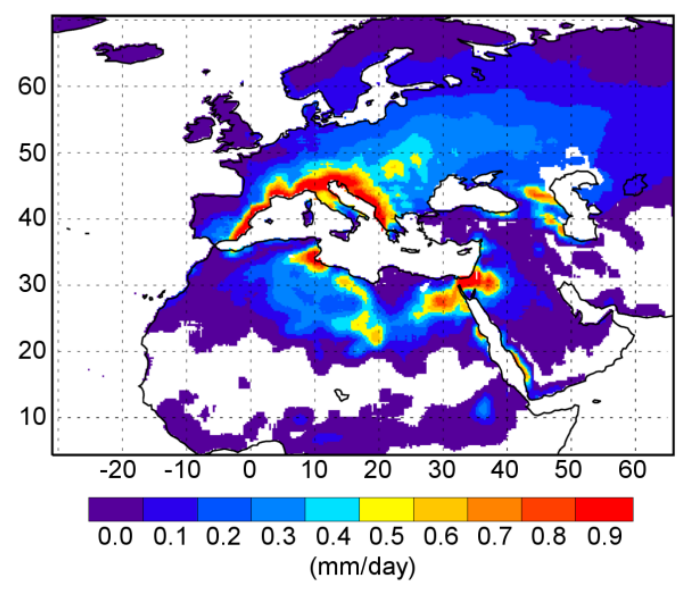

Figure 5. Monthly averaged value of E-P<0integrated during 10 days (PFLEX-Cli) for the period 1980-2015 obtained from the forward Lagrangian experiment for Mediterranean Sea during September.

We have also computed for the same 5 years grid by grid of maximum precipitation used to compose MSWEP-extreme the precipitation generated by moisture coming from the Mediterranean Sea as calculated by our Lagrangian experiment, namely from here as PFLEX-extreme.

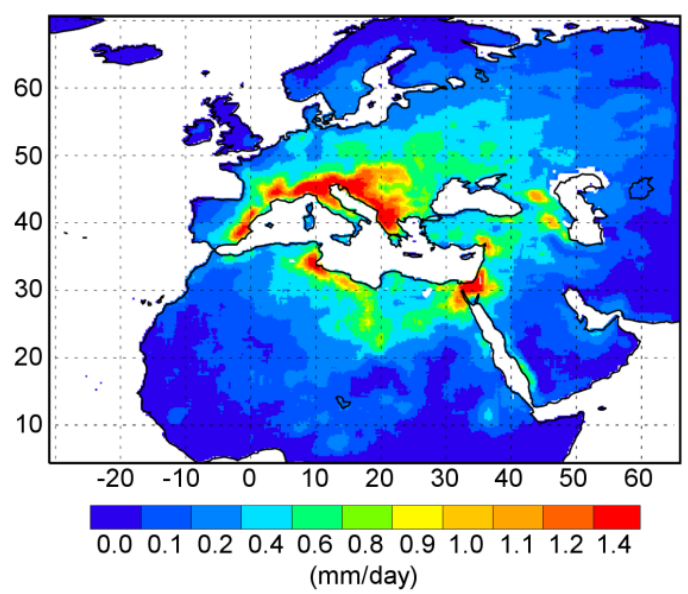

Figure 6. Mean precipitation for each grid point for the same 5 years with the highest value of precipitation (PFLEX-extreme) in September identified in MSWEP-extreme. Results are obtained from FLEXPART monthly precipitation data taking into account a 36 years temporal period (1980-2015).

These extreme E-P $<0$ values (PFLEX-extreme) shown in Figure 6 during September exhibits a similar geographical pattern as recorded by MSWEP-extreme, with expected lower values as these are due only by the moisture that comes from the Mediterranean Sea.

As for MSWEP results, Figure 7 shows the ratio between PFLEX-Cli and PFLEX-extreme. 


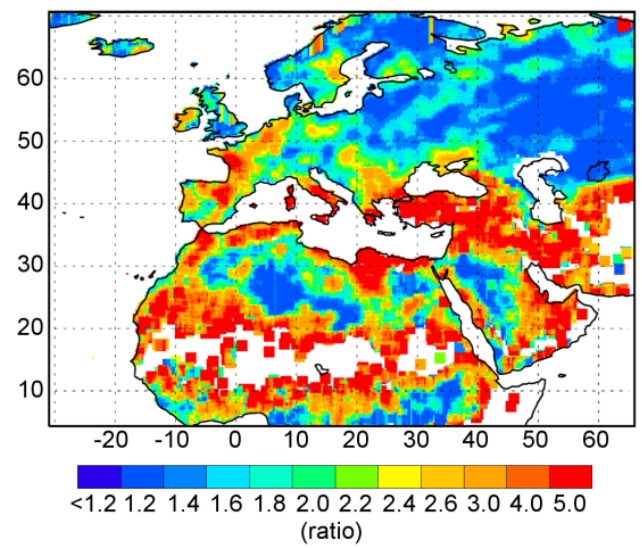

Figure 7. Ratio between mean values of the detected 5 years for each grid point with highest values of E-P $<0$ calculated using FLEXPART (PFLEX-extreme) and mean climatological values of E-P $<0$ (PFLEX-Cli) during September.

\subsection{Identification of differences between FLEXPART and MSWEP climatological monthly precipitation and} extreme monthly precipitation

To show the influence of the Mediterranean Sea moisture in the precipitation registered in the Mediterranean region during September, we have calculated the percentage between the mean climatological value of precipitation obtained via forward Lagrangian experiment (PFLEX-Cli) and the monthly climatological precipitation in the Mediterranean region (MSWEP-Cli) using the MSWEP precipitation dataset (Figure 8).

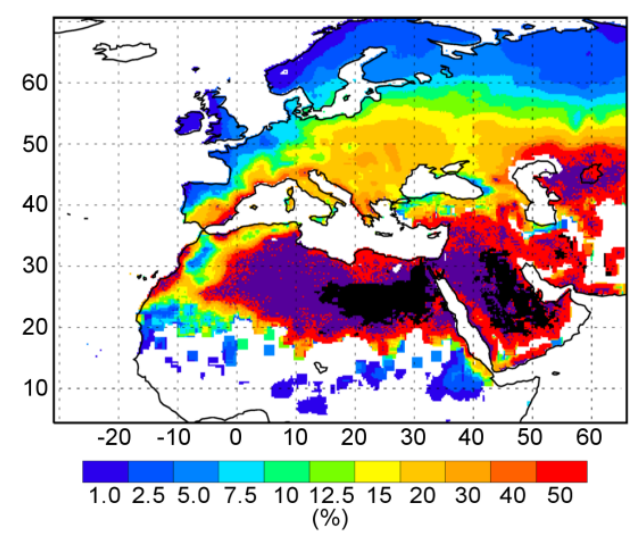

Figure 8. Monthly climatological percentage of the Mediterranean moisture contribution (PFLEX-Cli) in the precipitation (MSWEP-Cli) during September. Violet color represents where the percentage values are $100 \%$, and black color indicate regions where the MSWEP precipitation dataset does not show values.

Results show that the Mediterranean moisture has the highest contribution for the total precipitation over semiarid and arid regions in Africa, Middle East and Asia and over the north-western coast in Europe (values more than $40 \%$, orange and red colors). Important fraction of precipitation is located the Mediterranean coast of the Iberian Peninsula, France, Alpine regions and Greece; there are moderate contribution (with values between 20 and $40 \%$, oranges colors) over the Italian Peninsula, and Central Europe. Those results are in concordance with some previous works [28]. 
The same computation was done to check the percentage explained between monthly extreme precipitation values (PFLEX-extreme versus MSWEP-extreme) for 5 years with maximum values grid by grid during September (Figure 9).

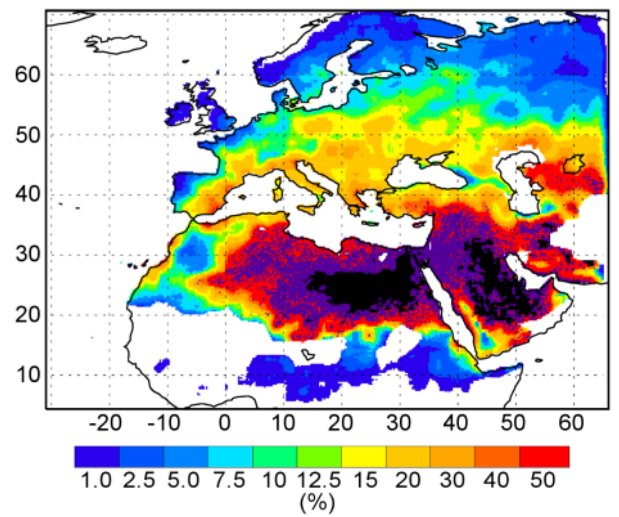

Figure 9. As Figure 8 but for the percentage between PFLEX-extreme and MSWEP-extreme.

From the Figure 9 we can conclude that the moisture that comes from the Mediterranean region during the years with the highest precipitations represents more than the $20 \%$ in the areas around the Mediterranean Sea.

\section{Conclusion.}

In general terms, the spatial pattern of the contribution of the Mediterranean source to the precipitation does not differ a lot between those years with higher precipitation and the climatology; however there any European regions where the Mediterranean is not an important source for climatological precipitation but it is a significant source for extreme precipitation years.

Acknowledgments: D. Ciric is supported by European Commission under the Erasmus Mundus Project Green-Tech-WB: Smart and Green Technologies for Innovative and Sustainable Societies in the Western Balkans (551984-EM-1-2014-1-ES-ERA Mundus-EMA2). This research was partially supported by Xunta de Galicia under project ED413C 2017/64 "Programa de Consolidacion e Estructuracion de Unidades de Investigacion Competitivas (Grupos de Referencia Competitiva)" co-funded by European Regional Development Fund (FEDER).

Author Contributions: D. Ciric, R. Nieto, and L. Gimeno conceived and designed the experiments; D. Ciric, L. Losada performed the experiments; D. Ciric, R. Nieto, and L. Gimeno analysed the data; D. Ciric, R. Nieto, A. Drumond and L. Gimeno wrote the paper.

Conflicts of Interest: The authors declare no conflict of interest. The founding sponsors had no role in the design of the study; in the collection, analyses, or interpretation of data; in the writing of the manuscript; and in the decision to publish the results. 
The 1st International Electronic Conference on Hydrological Cycle (CHyCle-2017), 12-16 November 2017; Sciforum Electronic Conference Series, Vol. 1, 2017

\section{References}

1. Gimeno, L.; Drumond, A.; Nieto, R.; Trigo, R.M.; Stohl, A. On the origin of continental precipitation. Geophys. Res. Lett. 2010, 3, L13804, doi: 10.1029/2010GL043712.

2. Gomez-Hernandez, M; Drumond, A; Gimeno, L; Garcia-Herrera, R. Variability of moisture sources in the Mediterranean region during the period 1980-2000. Water Resources Research 2013, 49, 6781-6794, doi: 10.1002/wrcr.20538.

3. R, Nieto; L, Gimeno; A, Drumond; E, Hernandez. A Lagrangian identification of the main moisture sources and sinks affecting the Mediterranean area. Wseas Ttransactions on Environment and Development 2010, 6, 1790-5079.

4. Westra, S; Alexander, L.V.; Zwiers, F.W. Global Increasing Trends in Annual Maximum Daily Precipitation. Journal of Climate 2013, 26, 3904-3918, doi: 10.1175/JCLI-D-12-00502.1.

5. Alexander, L. V.; Zhang, X.; Peterson, T.C.; Caesar, J.; Gleason, B.; Klein Tank, A.M.G. et al. Global observed changes in daily climate extremes of temperature and precipitation. Journal of Geophysical Research 2006, 111, D05109, doi: 10.1029/2005JD006290.

6. EASAC. Trends in Extreme Weather Events in Europe: Implications for National and European Union Adaptation Strategies; EASAC Policy Report 22; European Academies Science Advisory Council: Halle, Germany, 2013; Available online: www.easac.eu (accessed on 30 October 2017).

7. Lionello, P.; Malanotte-Rizzoli, P.; Boscolo, R.; Alpert, P.; Artale, V. et al. The Mediterranean climate: an overview of the main characteristics and issues, Mediterranean Climate Variability. Developments in Earth \& Environmental Sciences 2006, 4, 1-26, doi: 10.1016/S1571-9197(06)80003-0.

8. Gualdi, S.; Somot, S.; Li, L.; Artale, V.; Adani, M. et al. The CIRCE Simulations Regional Climate Change Projections with Realistic Representation of the Mediterranean Sea. Bulletin of the American Meteorological Society, American Metorological Society, 2013, 94, 65-81. doi: 10.1175/BAMS-D-11-00136.1.

9. Raveh-Rubin, S; and Wernli; H. Large-scale wind and precipitation extremes in the Mediterranean: a climatological analysis for 1979-2012. Quarterly Journal of the Royal Meteorological Society 2015, 141, 2404-2417, doi:10.1002/qj.2531.

10. Winschall, A.; Sodemann, H.; Pfahl, S.; Wernli, H. How important is intensified evaporation for Mediterranean precipitation extremes? Journal of Geophysical Research-Atmospheres 2014, 119, 5240-5256, doi:10.1002/2013JD021175.

11. Ciric, D.; Nieto, R.; Ramos, A.M.; Drumond, A.; Gimeno, L. Wet Spells and Associated Moisture Sources Anomalies across Danube River Basin. Water 2017, 9, 615, doi: 10.3390/w9080615.

12. Knippertz, P.; Martin, J. E. Tropical plumes and extreme precipitation in subtropical and tropical West Africa. Quarterly Journal of the Royal Meteorological Society 2005, 131, 2337-2365, doi:10.1256/qj.04.148.

13. Pinto, J. G.; Ulbrich, S.; Parodi, A.; Rudari, R.; Boni, G.; Ulbrich, U. Identification and ranking of extraordinary rainfall events over Northwest Italy: The role of Atlantic moisture, Journal of Geophysical Researh Atmospheres 2013, 118, 2085-2097, doi:10.1002/jgrd.50179.

14. Dayan, U.; Nissen, K.; Ulbrich, U. Review Article: Atmospheric conditions inducing extreme precipitation over the eastern and western Mediterranean. Natural Hazards and Earth System Sciences 2015, 15, 2525-2544, doi:10.5194/nhess-15-2525-2015.

15. Dayan, U.; Ziv, B.; Margalit, A.; Morin, E.; Sharon, D. A severe autumn storm over the Middle-East: Synoptic and Mesoscale convection. Theoretical and Applied Climatology 2001, 69, 103-122, doi: 10.1007/s007040170038.

16. Homar, V.; Stensrud, D. J. Sensitivities of an intense Mediterranean cyclone: Analysis and validation. Quarterly Journal of the Royal Meteorological Society 2004, 130, 2519-2540, doi:10.1256/qj.03.85.

17. Kotroni, V.; Lagouvardos, K.; Defer, E.; Dietrich, S.; Porcu, F.; Medaglia, C. M.; Demirtas, M. The Antalya 5 December 2002 storm: Observations and model analysis. Journal of Applied Meteorology and Climatology 2006, 45, 576-590, doi:10.1175/JAM2347.1.

18. Xoplaki, E.; Gonzalez-Rouco, J. F.; Luterbacher, J. Wet season Mediterranean precipitation variability: Influence of large-scale dynamics and trends. Climate Dynamics 2004, 23, 63-78, doi:10.1007/s00382-004-0422-0.

19. Massacand, A. C.; Wernli, H.; Davies, H. C. Heavy precipitation on the alpine southside: An upper-level precursor. Geophysical Research Letters 1998, 25, 1435-1438, doi:10.1029/98GL50869. 
The 1st International Electronic Conference on Hydrological Cycle (CHyCle-2017), 12-16 November 2017;

Sciforum Electronic Conference Series, Vol. 1, 2017

20. Gaetani, M..; Baldi, M.; Dalu, G.A.; Maracchi, G. Jetstream and rainfall distribution in the Mediterranean region. Natural Hazard and Earth System Sciences 2011, 11, 2469-2481, doi: 10.5194/nhess-11-2469-2011.

21. Hurrell, J. W. Decadal trends in the North Atlantic Oscillation: regional temperature and precipitation. Science 1995, 269, 676-679, URL:http://www.jstor.org/stable/2888966.

22. Llasat ,M. C.; Llasat-Botija , M.; Prat, M. A.; Porcu, F.; Price, C. et al. High-impact floods and flash floods in Mediterranean countries: the FLASH preliminary database. Advances in Geosciences 2010, 23, 47-55, doi: 10.5194/adgeo-23-47-2010.

23. Alpert, P.; Ben-Gai, T.; Baharad, A.; Benjamini, Y.; Yekutieli, D.; Colacino, M.; Diodato, L.; Ramis, C.; Homar, V.; Romero, R.; Michaelides, S.; Manes, A. The paradoxical increase of Mediterranean extreme daily rainfall in spite of decrease in total values. Geophysical Research Letters 2002, 29, 0, doi: 10.1029/2001GL013554.

24. Kostopoulou, E.; Jones, PD. Assessment of climate extremes in the Eastern Mediterranean. Meteorology and Atmospheric Physics 2005, 89, 69-85, doi: 10.1007/s00703-005-0122-2.

25. Ciric, D.; Stojanovic, M.; Drumond, A.; Nieto, R.; Gimeno, L. Tracking the Origin of Moisture over the Danube River Basin Using a Lagrangian Approach. Atmosphere 2016, 7, 162, doi: 10.3390/atmos7120162.

26. Sodemann, H.; Zubler, E. Seasonal and inter-annual variability of the moisture sources for Alpine precipitation during 1995-2002. Int. J. Climatol. 2010, 30, 947-961, doi:10.1002/joc.1932.

27. Schicker, I.; Radanovics, S. and Seibert, P. Origin and transport of Mediterranean moisture and air. Atmospheric Chemistryand Physics 2010, 10, 5089-5105, doi:10.5194/acp-10-5089-2010.

28. R, Nieto; L, Gimeno; A, Drumond; E, Hernandez. A Lagrangian identification of the main moisture sources and sinks affecting the Mediterranean area. Wseas Transactions on Environment and Development 2010, 6, 1790-5079.

29. Nojarov, P. The increase in September precipitation in the Mediterranean region as a results of changes in atmospheric circulation. Meteorology and Atmospheric Physics 2017, 129, 146-156, doi: 10.1007/s00703-016-0463-z.

30. Mehta, A.V.; Yang, S. Precipitation climatology over Mediterranean Basin from ten years of TRMM measurements. Advances in Geosciences 2008, 17, 87-91.

31. Stohl, A.; James, P. A Lagrangian analysis of the atmospheric branch of the global water cycle. Part I: Method description, validation, and demonstration for the August 2002 flooding in central Europe. J. Hydrometeorol. 2004, 5, 656-678, doi: 10.1175/1525-7541(2004)005<0656:ALAOTA>2.0.CO;2.

32. Stohl, A.; James, P. A Lagrangian analysis of the atmospheric branch of the global water cycle: Part II: Moisture transports between Earth's ocean basins and river catchments. J. Hydrometeorol. 2005, 6, 961-984, doi: 10.1175/JHM470.1.

33. Beck, H.E.; van Dijk, A.I.J.M.; Levizzani,V.; Schellekens, J.; Miralles, D.G.; Martens, B.; de Roo, A. MSWEP: 3-hourly $0.25^{\circ}$ global gridded precipitation (1979-2015) by merging gauge, satellite, and reanalysis data, Hydrology and Earth System Sciences 2017, 21(1), 589-615, doi: 10.5194/hess-21-589-2017.

34. Beck, H. E.; Vergopolan, N.; Pan, M.; Levizzani,V.; van Dijk, A.I.J.M.; Weedon, G.P.; Brocca, L.; Pappenberger, F.; Huffman, G.J.; Wood, E.F. Global-scale evaluation of 23 precipitation datasets using gauge observations and hydrological modeling, Hydrology and Earth System Sciences Discussions, in review, 2017, doi:10.5194/hess-2017-508.

35. Dee, D.P.; Uppala, S.M.; Simmons, A.J.; Berrisford, P.; Poli, P.; Kobayashi, S.; Andrae, U.; Balmaseda, M.A.; Balsamo, G.; Bauer, P.; et al. The ERA-Interim reanalysis: Configuration and performance of the data assimilation system. Q.J. R. Meteorol. Soc. 2001, 137, 553-597, doi:10.1002/qj.828.

36. Numaguti, A. Origin and recycling processes of precipitating water over the Eurasian continent: Experiments using an atmospheric general circulation model. J. Geophys. Res. 1999, 104, 1957-1972, doi: 10.1029/1998JD200026.

37. Gimeno, L.; Stohl, A.; Trigo, R.M.; Domínguez, F.; Yoshimura, K.; Yu, L.; Drumond, A.; Durán-Quesada, A.M.; Nieto, R. Oceanic and Terrestrial Sources of Continental Precipitation. Rev. Geophys. 2012, 50, RG4003, doi: 10.1029/2012RG000389.

38. Mehta, A.V.; Yang, S.; Precipitation climatology over Mediterranean Basin from ten years of TRMM measurements. Advances in Geosciences 2008, 17, 87-91, doi: 10.5194/adgeo-17-87-2008. 
The 1st International Electronic Conference on Hydrological Cycle (CHyCle-2017), 12-16 November 2017; Sciforum Electronic Conference Series, Vol. 1, 2017

(C) 2017 by the authors; licensee MDPI, Basel, Switzerland. This article is an open access article distributed under (CC) the terms and conditions of the Creative Commons by Attribution (CC-BY) license (C) (http://creativecommons.org/licenses/by/4.0/). 